\title{
Common Beliefs and Research Evidence about Dyslexic Students' Specific Skills: Is it time to reassess some of the evidence?
}

\author{
Victor Martinelli ${ }^{1 *}$, Doriella Camilleri ${ }^{2}$, and Deidre Fenech ${ }^{2}$ \\ 'Department of Educational Studies, University of Malta, Malta \\ ${ }^{2}$ SpLD Service, Directorate for Learning and Assessment, Malta
}

\begin{abstract}
Empirical studies of the relationship between dyslexia and creativity and visuo-spatial skills are inconsistent. While some anecdotal evidence suggests that there is a positive association between dyslexia and creativity, other studies suggest that such an association emerges only in adulthood as a result of adverse life experiences. Others state that dyslexia is associated with weaker rather than enhanced creativity and visuo-spatial ability. The aim of this study was to examine whether adolescents with dyslexia possess superior creativity and visuo-spatial ability as measured by the Torrance Tests of Creative Thinking (TTCT) and two measures of visuo-spatialability, the Spatial Reasoning Test and the Virtual Bungalow Test. The participants in this study were secondary school students diagnosed with dyslexia and a group of students without dyslexia $(\mathrm{N}=76)$ matched for age, socioeconomic status and ability. In spite of some variation in the scores between the two matched groups on all the measures administered, the differences were not statistically significant. Overall, no support was found for the hypothesis that adolescents with dyslexia are highly creative or visuo-spatially endowed and it is advised that teachers treat learners with dyslexia like other learners with learning difficulties and not assume that

they possess compensatory skills.
\end{abstract}

Citation: Martinelli, V, Camilleri D, Fenech D.Common Beliefs and Research Evidence about Dyslexic Students' Specific Skills: Is it time to reassess some of the evidence? Interdisciplinary Education and Psychology. 2018; 2(2):4.

Received: June 11, 2018 Accepted: October 19, 2018 Published: November 1, 2018

Copyright: (๑) 2018 Martinelli. This is an open access article distributed under the terms of the Creative Commons Attribution License, which permits unrestricted use, distribution, and reproduction in any medium, provided the original author and source are credited.

Corresponding author: Victor Martinelli, Department of Educational Studies, Faculty of Education, University of Malta, Malta E-mail: victor.martinelli@um.edu.mt

\section{Keywords}

Creativity, visuo-spatial ability, dyslexia, teaching

\section{Introduction}

Dyslexia is a prevalent form of reading disorder that may lead to "disengagement with the educational system... behavioural problems, social exclusion and crime and reduced employment prospects (which in turn make mental ill-health more likely)" (Beddington et al., 2008, p. 1060). Dyslexia is manifested in all languages including those with a non-alphabetic character system such as Chinese and Japanese (Sun, Lee, \& Kirby, 2010). It is estimated that it affects up to $10 \%$ of the population of the United States of America (Siegel, 2006) and Australia (Vidyasagar \& Pammer, 2009). In the United Kingdom, Peterson and Pennington (2012) quote an incidence of $7 \%$. On the contrary, only about $3 \%$ of the Italian population of school-age children is estimated to have dyslexia (Barbiero et al., 2012). Research also shows that dyslexia is two or three times more prevalent in males than in females (Rutter et al., 2004) and represents the most common type of learning difficulty among individuals with a learning disability (Lyon, Shaywitz, \& Shaywitz, 2003).

Niolaki and Masterson (2012) report that in the context of the Greek language which is considered to be orthographically shallow, monolingual Greek children's spelling performance was predicted by their phonological awareness. Martinelli (1996) indicated that in the context of the smaller grain size of Maltese phonology and its shallow orthographic structure, measures of phonological awareness are better predictors of competent reading (in Maltese) than are measures of rhyme awareness. Moreover, in a comparative study on the 
use of typical predictors of reading commonly used in English with young children, Brincat (2017) identified a phoneme elision task in Maltese, a measure of phonological manipulation, to be the strongest $(\beta=.42)$ significant predictor for Maltese word reading. This would lead one to predict that in such situations of shallow orthographies and small phonological grain size, dyslexic readers reading Maltese would still read quite accurately if slowly. Maltese dyslexics typically struggle with both English and to a lesser extent, Maltese reading and writing but certainly their situation is more complex than that of the monolingual child (Firman, 2009).In spite of the difficulties that dyslexic children experience (Elliott, 2005; Elliott \& Gibbs, 2008; Elliott \& Place, 2004; Rice \& Brooks, 2004) some describe it as a 'gift', often accompanied by creativity, intuition and problem-solving skills (Davis \& Braun, 2010). Others describe it as some sort of an advantage rather than a learning difficulty (Tafti \& Faizipour, 2005; Tafti, Hameedy, \& Baghal, 2009).

Dyslexia has attracted much attention within the research community (Williams \& O'Donovan, 2006). The International Dyslexia Association defines the condition in the following way and this definition is supported by practitioners and professionals alike (Cain, 2010):

Dyslexia is ... characterized by difficulties with accurate and/or fluent word recognition and by poor spelling and decoding abilities. These difficulties typically result from a deficit in the phonological component of language that is often unexpected in relation to other cognitive abilities and the provision of effective classroom instruction. Secondary consequences may include problems in reading comprehension and reduced reading experience that can impede the growth of vocabulary and background knowledge. (Lyon et al., 2003, p. 2)

The influential Rose Report (2009) lists other characteristics of individuals with dyslexia, including their increased design, problem-solving, creative, interactive, and oral skills. Other studies demonstrate that individuals with dyslexia are over represented in art- and designrelated disciplines utilising visuo-spatial and creative abilities (Symonds, 2005; Winner, Casey, DeSilva, \& Hayes, 1991; Winner et al., 2001; Wolff, 2011; Wolff \& Lundberg, 2002). These findings are consistent with the Geschwind and Galaburda (1987) pathology of superiority theory, which includes a wide array of characteristics that individuals with dyslexia possess; increased design, problem-solving, creative, interactive, and oral skills. Chamberlain, Brunswick, Siev, and McManus (2018) describe this enhancement as the predominantly left hemispheric pathology seen in dyslexia, leading to enhanced functioning of the non-pathological right hemisphere. However, they report that this view is not without its detractors like Bryden, McManus, \& Bulman-Fleming (1994) who criticise the cerebral lateralization model, suggesting that it is not well supported by empirical evidence. Gilger, Allen, \& Castillo's (2016) review of the issue of the dyslexic advantage suggests that such groups do not perform better on dynamic spatial reasoning tasks than controls and that they are more likely to perform worse than, or equal to, controls. However, typical of the ongoing discussion on the subject, Gilger et al. (2016) do not close the door on possible dyslexic talents, stating that the neurodiversity of the dyslexic brain may be expressed in absolute or relative talents in a number of cognitive or personality domains. Chamberlain et al. (2018) in a large meta-analytic study of 909 non-dyslexic and 956 dyslexic individuals suggested that dyslexia is associated with a lower mean performance on visuo-spatial tasks assessing ability for imagery, memory, and perception. They also noted greater variability in the performance of the dyslexic participants with larger effect sizes (and SDs) for imagery and memory tasks and smaller effect sizes (and SDs) for perceptual tasks.

The operationalisation of these constructs is normally effected through standardised measures of creativity and visuo-spatial ability but there is much controversy as to what extent and which aspect of the construct they actually assess (Carroll, 1993). There are numerous tests that have been validated over time that are respected by the academic community but the diverse nature of the problem is such that the interpretation of the construct varies according to what the researcher defines it to be (Chamberlain et al., 2018). One also needs to consider the heterogeneity of the participant samples and heterogeneity of tasks used in relevant studies leading to different interpretations and results (Gilger et al., 2016). The operationalisation of the term "dyslexia" and cut-off levels of difficulty that are considered to typify the condition constitutes yet another level of interpretability in the quest for an increasingly elusive answer to the question of creative and spatial endowment in dyslexia. 


\section{Dyslexia, Creativity and Divergent thinking}

Torrance (1966) defines creativity as:

a process of becoming sensitive to problems, deficiencies, gaps in knowledge, missing elements, disharmonies, and so on; identifying the difficulty; searching for solutions, making guesses, or formulating hypotheses about the deficiencies: testing and retesting these hypotheses and possibly modifying and retesting them; and finally communicating the results. (p. 8)

Studies that link dyslexia with creativity and artistic talents span four decades (Galaburda, Sherman, Rosen, Aboitiz, \& Geschwind, 1985; Geschwind \& Galaburda 1987; West, 1999; Wolf \& Lundberg, 2002). Miles (1993) and McLoughlin, Fitzgibbon, and Young (1994) cite several cases where adults with dyslexia have been noted to use compensatory creative strategies and become successful in occupations that require creative abilities. Everatt, Steffert, and Smythe (1999), as well as Everatt, Weeks, and Brooks (2008) support the view that adults with dyslexia are more successful than others in solving tasks that require creativity and that adults with dyslexia are more likely to view themselves as creative than do controls.

Tafti et al. (2009) compared Iranian school-age children with dyslexia and their matches without dyslexia on the Torrance Tests of Creative Thinking (TTCT). They described their research participants as having significantly higher performance in originality and synthesis. Cockcroft and Hartgill (2004) report similar results with school-age children with dyslexia who performed significantly better than the normative group on the fluency subtest of the TTCT. Conversely, Ritchie, Luciano, Hansell, Wright, and Bates (2013) report quite clearly that poor literacy ability in their study was associated with lower, rather than higher scores on all measures of creativity, even when controlling for IQ. Wolff (2011) suggests that there is some evidence, albeit inconsistent, that individuals with superior creative skills constitute a subgroup of the population with dyslexia but that not all of the population with this condition is endowed with high creativity.

The complex nature of creativity is difficult to assess (Villalba, 2012) but the cognitivepsychometric approach strongly influenced the assessment of creativity within educational contexts (Kozbelt, Beghetto, \& Runco, 2010). The Torrance Tests of Creative Thinking (TTCT), inspired by Guildford's (1966) Structure of Intellect model, is used in the present study because the TTCT is a robust measure of divergent thinking and the role this plays in certain kinds of creative expression and achievement (Runco, Millar, Acar, \& Cramond, 2010). If divergent thinking is a critical element of creative performance as argued by Runco (1990) then the two cannot be separated completely. These measures of creativity are recommended as the best-standardized measures to use because of the preponderance of evidence of their reliability and validity over time and in different cultures (Cramond, Matthews-Morgan, Torrance, \& Zuo, 1999). This makes them valid and reliable measures for assessing creativity in the general population (Kim, 2006). Creativity, as conceived in the TTCT, involves innovation, novelty, and insightfulness (Wolff, 2011). In the light of the possibility that the dyslexic profile possibly constitutes what Geschwind over 20 years ago referred to as a pathology of superiority (Sherman \& Cowen, 2010), the robustness of the tests was considered to be adequate for researching this area.

Everatt et al. $(1999,2008)$ support the view that adults with dyslexia are more successful than others in solving tasks that require creativity. Tafti et al. (2009) concluded that in their research, participants with dyslexia performed significantly better in two of the TTCT's sections, Originality and Synthesis. Cockcroft and Hartgill (2004) reported similar results with school-age children with dyslexia who performed significantly better than the normative group on the fluency subtest of the TTCT. The TTCT battery has been revised four times since its initial publication in 1966 (Plucker \& Makel, 2010) and this constant research and updating has contributed to why the tests remain so popular and well considered in educational applications (Kim, 2006; Kaufman, Plucker, \& Baer, 2008). This is not to say that the TTCT does not have its detractors. Baer (2011a; 2011b) lists a number of limitations related to the domain specificity of the tests. Baer (2011b) also makes a case for the inability of some of the tests to predict creative potential, thereby reinforcing the notion of domain specificity. The fact remains, however, that the TTCT is a widely available measure of creativity that is well regarded and widely researched. When one considers the pros and cons of the TTCT, there is much more evidence supporting their use than is otherwise the case (Cramond et al., 1999). Nevertheless, these limitations are to be kept in mind at all times. In support of the TTCT's 
robustness and adaptability, Torrance (1998) reported reliability coefficients of .9 and the battery has shown high reliability in multicultural settings too (Chávez-Eakle, 2010). Wang (2016) found no significant difference in creativity scores of English and Chinese speaking participants, showing that English ability was not a critical factor in the TTCT. To the author's knowledge, the TTCT has only been used in the dyslexic context with participants whose first language is other than English once in an Iranian context by Tafti et al. (2009).

\section{Dyslexia and Visuo-spatial ability}

Studies into the association of dyslexia with higher visuo-spatial abilities also span four decades (Galaburda \& Kemper, 1979; Galaburda et al.,1985; Rimland \& Fein, 1988; West, 1991, 1999; Wolf \& Lundberg, 2002). An article compiled from Geshwind's writings (Sherman \& Cowen, 2010) also referred to possible advantages a person with dyslexia may possess; "the very same anomalies on the left side of the brain that have led to the disability of dyslexia in certain literate societies also determine superiority in the same brains" (p. 15).According to Lubinski (2010), spatial talent is a salient characteristic of young adolescents studying science, technology, engineering, or mathematics (STEM) and is a good predictor of later educational achievement in STEM areas. Gardner (1993) also emphasizes that spatial ability determines students' progress in the sciences. Despite strong evidence that spatial ability is a good predictor of success in many areas of life (Lohman, 1994; Lubinski, 2010; Mohler, 2008) this important dimension of human ability is not fully recognised. Major international literacy policy initiatives such as the United Nations Literacy Decade: 2003-2012, UNESCO's Literacy Initiative for Empowerment (LIFE) and the European Commission's European Policy Network of National Literacy Organisations emphasize the importance of acquiring basic proficiency in literacy, numeracy and digital literacy but they rarely refer to spatial ability. Numerous researchers (e.g. Shea, Lubinski, \& Benbow, 2001; Geschwind \& Galaburda, 1987 ) argue that education systems cannot afford to neglect this crucial feature of the "human cognitive repertoire" (Shea et al., 2001, p. 612). If one does so, then one ignores a small but significant pool of resources in our population, this apart from frustrated occupational goals and loss of potential careers.

Currently, research in the area of visuo-spatial ability is conducted using two-dimensional tests on paper and simulated three-dimensional computer-generated tests (Rizzo, Parsons, Kenny, \& Buckwalter, 2012). Duranovic, Dedeic, and Gavrić (2015) used the two-dimensional method to study whether students with dyslexia exhibited superior visualisation strategies. They used the Paper Folding Test (Ekstrom, French, Harman, \& Dermen, 1976) to assess how accurately participants could predict how a piece of a paper would look after it had been folded, punched with a hole and unfolded once again. Duranovic et al. (2015) used this test to research differences in analytical and mental visualisation techniques among students with dyslexia. They found no consistent differences between their matched dyslexic and average readers. Brunswick, Martin, and Marzano (2010) asked participants to reproduce designs and recall the direction of the Queen's head on a stamp to explore differences in the visuo-spatial skills of dyslexic and non-dyslexic participants. Contrary to predictions, they found no tasks on which the dyslexic readers as a group outperformed the unimpaired readers, but they did find several sex-by-group interactions. Winner et al. (2001) used two-dimensional tests, the Vandenberg Test of Mental Rotation, and the copying task of the Rey-Osterrieth Complex Figure (ROCF) with adolescents with dyslexia. In their study, individuals with dyslexia showed no advantage on a wide variety of spatial tasks, including visualization, mental rotation, memory, visual scanning, and orientation. Tosto et al. (2014) used the Spatial Reasoning Test (Smith \& Lord, 2002a), the exact same test as used in this study to explore aetiological links between visuo-spatial and mathematical ability, but not differences in spatial awareness between dyslexic and non-dyslexic readers. Helland and Asbjørnsen (2003) used subtests from the Aston Index, the Rey-Osterieth Complex Figure Test, and the Wechsler Intelligence Scale for Children-Revised (which are primarily two-dimensional paper tests with the one exception of some subtests of the WISC-R) in their study. They made a case for the underlying causes of dyslexia being not only a phonological impairment but also language comprehension impairment. Contrary to other research studies quoted above, they also identified visuo-spatial impairment as an underlying cause of dyslexia. They claimed that visuo-spatial skills should be evaluated as a separate indicator of dyslexia, along with an evaluation of language comprehension and mathematics skills. This list of studies employing two-dimensional tests on paper and their uses has been compiled as evidence that two- 
dimensional tests on paper have been used successfully to measure various aspects of visuospatial abilities.

Non-immersive computer-based visuo-spatial ability programmes hold promise for studying visuo-spatial ability but this technology is still limited. Von Károlyi (2001) and von Károlyi, Winner, Gray, and Sherman (2003) posited the diverging ability hypothesis. They predicted that dyslexic individuals perform better on a global task, identifying impossible figures, and performed worse on a feature-oriented task, like matching figures. Von Károlyi (2001) used two computer-based visuo-spatial tasks, the Impossible Figures and the Celtic Matching Task to research visuo-spatial skills in participants with dyslexia. In the Impossible Figures Task, designed to assess right-hemisphere mediated global visuo-spatial discrimination, participants were requested to identify impossible line drawings of threedimensional objects by observing various features simultaneously. The Celtic Matching Task was designed to assess local visuo-spatial processing, engaging primarily the left hemisphere of the brain. Von Károlyi et al. (2003) attempted to replicate results from her earlier 2001 study for the Impossible Figures Task. Her hypotheses were partially supported but her results were far from conclusive. The most consistent dyslexic disadvantage was seen on tasks measuring spatial rotation ability, while a dyslexic advantage was most commonly seen on tasks measuring holistic visual processing and perceptual closure, such as the Impossible Figures Test (von Károlyi, 2001; von Károlyi et al., 2003).

Wang and Yang (2011) created a virtual environment test to compare the visuo-spatial abilities of students with dyslexia and non-dyslexic students. Ten to twelve-year-old participants were instructed to manipulate the objects presented on the computer screen by pressing the mouse and rotating three-dimensional figures to find a hidden ball. The proportions of correct responses of dyslexic and average male and female participants were not significantly different in the Wang and Yang (2011) study but they did register some gender differences that are beyond the scope of this present review.

Attree, Turner, and Cowell (2009) used a computer-generated virtual environment test when measuring the visuo-spatial abilities of participants with dyslexia. This task was presented on a computer screen and participants were required to navigate their way through a virtual bungalow using a keyboard and complete some memory tasks immediately after. On this task, teenagers with dyslexia demonstrated better visuo-spatial orientation, visualisation and reference memory than non-dyslexic peers. Although the authors were somewhat circumspect about these positive findings and emphasised the need for their results to be replicated, their results supported the possibility that dyslexia could be associated with superior performance on assessments that reflect real-world tasks.

\section{Method}

\section{Participants and their schools}

In this study, a group of 38 mixed-gender adolescents with dyslexia aged between 12 and 14 years was compared to a matched group of students on aspects of creativity and visuo-spatial skills. These participants were, at the time of the study, being supported by the Specific Learning Difficulties Service that is one of a number of services provided by Central Government to support the state education sector. These participants came from three different Colleges in Malta, purposely selected to cover the northern, the central, and the southern localities of the island to ensure adequate geographic representation. Participants with dyslexia and their matches were evenly distributed across the three Colleges and matches were selected from the same. Given that access to state school education is free and that there are costlier alternatives, there is a tendency for state school children to come from the less affluent socioeconomic classes. In a study by Martinelli and Schembri (2015), children attending state secondary education came from homes where the main wage earner was in a routine, largely manual occupation as described in the Socio-economic Classification 2010 (Office for National Statistics, U.K.).

The term "College" in the state education sector refers to a secondary school and its feeder primary schools. All Colleges share a common curriculum and a system of setting for the core subjects. There is no selection process to enter the state school system at whatever level and students can transfer from one college to another seamlessly, although there is setting by core subjects. Participants in this study may be representative of students attending the state school system only but do not represent students attending Independent (private) or Church 
schools. During the scholastic year 2014-2015, of the 4,032 twelve-year-olds attending school in Malta, only $52 \%$ were being educated in the state school system (NSO News Release $202 / 2016$ ). Of the remaining number, $37 \%$, and $11 \%$ of 12 -year-olds were following their education in Church and Independent schools. These percentages apply to 13 and 14year-old students too, give or take a percentage point.

Although children attending all schools in Malta are expected to develop written and spoken competence in both English and Maltese (Firman, 2009), knowledge of the two languages varies considerably depending on geographical location, parents' level of education, and socio-economic background (Sciriha \& Vassallo, 1998). Grech (2011) claimed that on a wellrespected English reading comprehension test (Neale Analysis of Reading Ability), Maltese school-age children's achievement was about two years below that of British children. This gives the reader an indication that on average, Maltese children's accuracy and reading comprehension in English lags behind that of their UK peers by about two years. Personal experience suggests that there is much variation, depending on the school sector and socioeconomic status.

All 38 participants with dyslexia possessed average intelligence quotients (85-115), this being indicated in their statement of special educational needs. These adolescents were paired with matched peers from the designated pool of students in terms of age, gender and socio-economic background. The IQ of the group of participants without dyslexia could not be measured directly through testing but all the members of this group were specifically selected from average groups for English language classes with the help of school administrators who confirmed their status as average achievers. Controlling for ability was necessary to minimise the possibility that differences in the participants' eventual results would not be attributable to differences in intelligence but rather, to creative or visuo-spatial potential. The researchers used the Suffolk English Reading Comprehension Test Level 2 (Hagley, 2002) with Maltese norms (University of Malta/Ministry of Education, 2010) to confirm the presence of reading difficulties in the individuals with dyslexia. As expected, the majority of participants with dyslexia scored below the cut-off score of 85 deviation points in their reading comprehension in English (bottom 16\% of the population). A few participants who obtained a reading score between 85 and 90 deviation points (bottom $25 \%$ of the population) were also included in the research group in view of the limited number of participants satisfying the criterion for admission to the study. All the participants' levels of creativity as defined by the tests used were assessed through the TTCT-Figural component. The participants' visuo-spatialabilities were assessed through the Spatial Reasoning Test (Smith \& Lord, 2002a) and the Virtual Bungalow test that is similar to the one used by Attree et al. (2009). All procedures followed were in accordance with the ethical standards of the institutional research ethics committee. This study was also approved by the school administrators and parents of those children recruited to participate in it. All participants were old enough to give their consent (as opposed to assent) to participate in this study. All measures had been pilot tested and minor modifications to the test procedure were made when necessary. One such change was the decision to give instructions in both English and Maltese. Gauci and Camilleri Grima (2012) describe how in Malta code switching prevails in teaching with the learners' first language, usually Maltese, being used as a pedagogical tool to enhance learning, making for more learner-friendly explanations and to get learners more directly involved in activities.

\section{Assessments}

The TTCT battery comprises a number of different verbal and figural components but in this study, only the figural components were used because the verbal skills of students with dyslexia could be affected by their learning difficulty. In addition, the figural component is more suitable for bilingual students (Eisen, 2001). The TTCT figural component includes picture construction, picture completion, and repeated parallel line tasks. The reported reliability coefficients of the TTCT tests (Torrance, 1998) ranged from .89 to .94 for fluency, flexibility, originality, and elaboration respectively. The TTCT-Figural Manual of 1990 quotes an interrater reliability among the scorers for Scholastic Testing Service, Inc., being greater than .90. In terms of the extent to which different tests of creativity and divergent thinking correlate when administered to the same participants or matched groups, Diakidoy and Spanoudis (2002) suggest that all tests of creativity do not tap exactly the same skills. Clapham (2004) suggested that the TTCT assesses a specific type of divergent thinking and creativity. Diakidoy \& Spanoudis (2002) suggested that domain and content specificity appear to affect 
all aspects of test use and interpretation.

The TTCT-Figural Form A was administered by the second author who is a teacher by profession and who works with children on a daily basis. This researcher was trained in the tests' administration and recording and had spent time prior to the study being monitored in the use of the TTCT by another experienced user. The tests were administered in a quiet room in a one-to-one setting and participants took about one hour to complete the tasks set. Instructions were given in English and repeated in Maltese. Participants were asked to draw pictures, following the instructions in the test manual. Five measures of creativity and divergent thinking were computed from this measure. Cronbach's alpha for the items in the TTCT-Figural Form was computed at .8 and the inter-item correlation averaged at .4, ranging from .1 to .9.

The Spatial Reasoning Test (Smith \& Lord, 2002a), is an example of a class of reasoning measures that taps the capacity to think about objects in three dimensions and to mentally manipulate presented drawings three-dimensionally from two-dimensional drawings. Spatial reasoning is "the ability to see, inspect, and reflect on spatial objects, images, relationships and transformations" (Battista, 2007, p.843). This test was administered by the second named contributor who is also a teacher by profession and the instructions were given in English and repeated in Maltese as required, always following the prescribed procedures. Like in the former case, she too administered the tests in a quiet room in a one-to-one setting. Five scores of different examples of visuo-spatial ability were computed from this measure. Cronbach's alpha for the items in the test was computed at .7 and the inter-item correlation averaged at .3, ranging from .2 to .5 .

The Virtual Bungalow spatial visualization task was also individually administered by the third author in a quiet room. Verbal instructions were given as described for the other two measures. The task was presented on a colour 18-inch screen laptop and included 2D-3D transformations (2D representations of $3 \mathrm{D}$ objects and isometric drawings). The Virtual Bungalow test measured spatial orientation and visualization and reference memory. It proved difficult to obtain the original software used by Attree et al., (2009) and a similar test was commissioned based on the information gleaned from the Attree et al. article. The new form of the Virtual Bungalow test was developed for this study by using Unity ${ }^{\circledR}$ software (Unity Technologies ApS, 2015), a cross-platform game engine. The Virtual Bungalow Test depicted four interconnected rooms in a house - a bedroom, a music room, a sitting room, and a kitchen, each identified by a related piece of furniture or fixture (see floor plan in Figure 1 below). A door and a corridor led participants from one room to the other where several household objects were scattered on the floor, such as an oil can, a billiard ball, a first-aid kit and a broomstick. Twenty-one test items were placed around the virtual bungalow. No test item typically associated with the function of the room was placed in any of the rooms. Participants were told specifically "You are about to enter a virtual house. Take your time to navigate through the rooms. You will find several objects lying around. Your aim is to observe the position of each object and the layout of the house. Please note that once you go out of a room you are not permitted to go back into it."

Once participants navigated their way through the bungalow, they were requested to sit on another table away from the laptop. The researcher presented them with a set of 37 picture cards containing images of all the household items in the bungalow, including 16 distractors that had never been presented before. Students were requested to select the images they remembered seeing inside the virtual house. This picture recognition test tapped the visual domain within the visuo-spatial sketchpad (Baddeley \& Hitch, 1974), by assessing immediate recall of object memory. After five minutes, the researcher collected the selected cards and instructed participants to replicate the spatial layout of the virtual setting. This task consisted of constructing a plan of the house using $2 \mathrm{D}$ cardboard shapes that had been designed in proportion to the actual dimensions of each room. Thus, incidental memory for the spatial layout was tested by analysing how participants perceived and remembered the virtual environment and its spatial orientation. This task constituted a second attempt at targeting the spatial domain within the visuo-spatial sketchpad (Baddeley \& Hitch, 1974). Once this plan was constructed, the researcher took pictures of the product so that the visuo-spatial ability of both groups could be easily compared. Finally, participants were given an A3 sheet of paper depicting the correct layout of the virtual bungalow. Pictures of the objects which were earlier identified as being present in the virtual bungalow were handed once again to the participants. Participants were requested to write down the corresponding number of each picture onto the 
plan in order to show the exact location where each object was placed. The aim of this task was to assess object-location memory. The scoring system used was identical to that used by Attree et al. (2009). Three scores were computed from this test, Object Memory, Spatial Memory and Object-Location Memory. Cronbach's alpha for the items in the test was computed at .7 and the inter-item correlation averaged at .5, ranging from .2 to .7.In this study, the aim was to compare the scores of the participants with dyslexia and matched peers without dyslexia. It was not deemed necessary to compare the results with any of the published norms of the tests used because the author was only interested in comparing the relative performance of the two groups of students in the study.

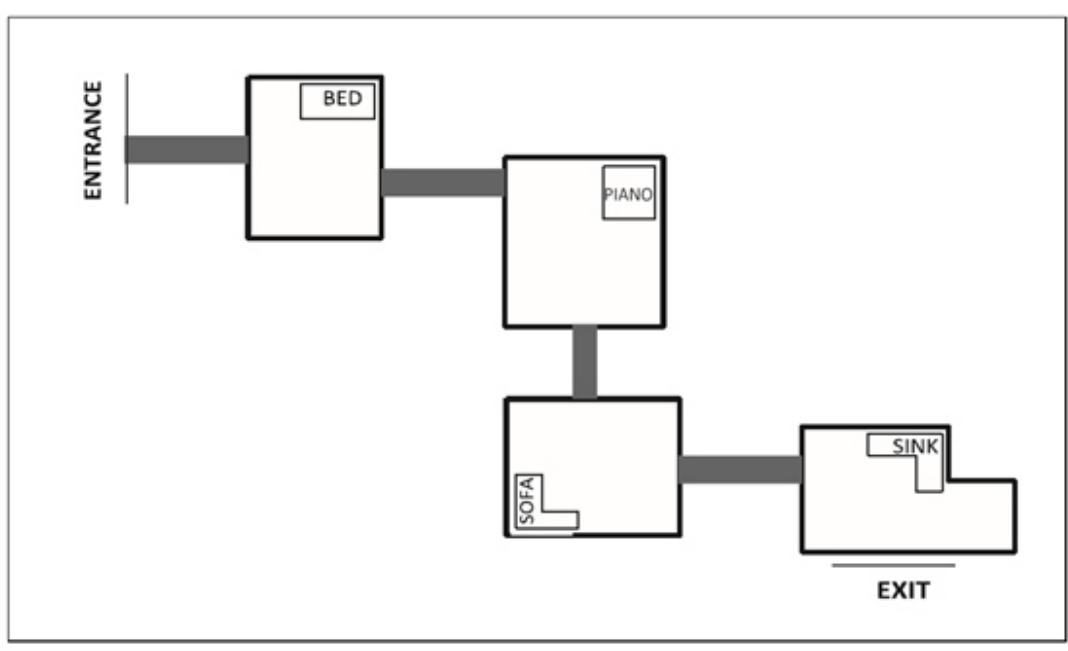

Figure 1. Schematic drawing of the Virtual Bungalow layout

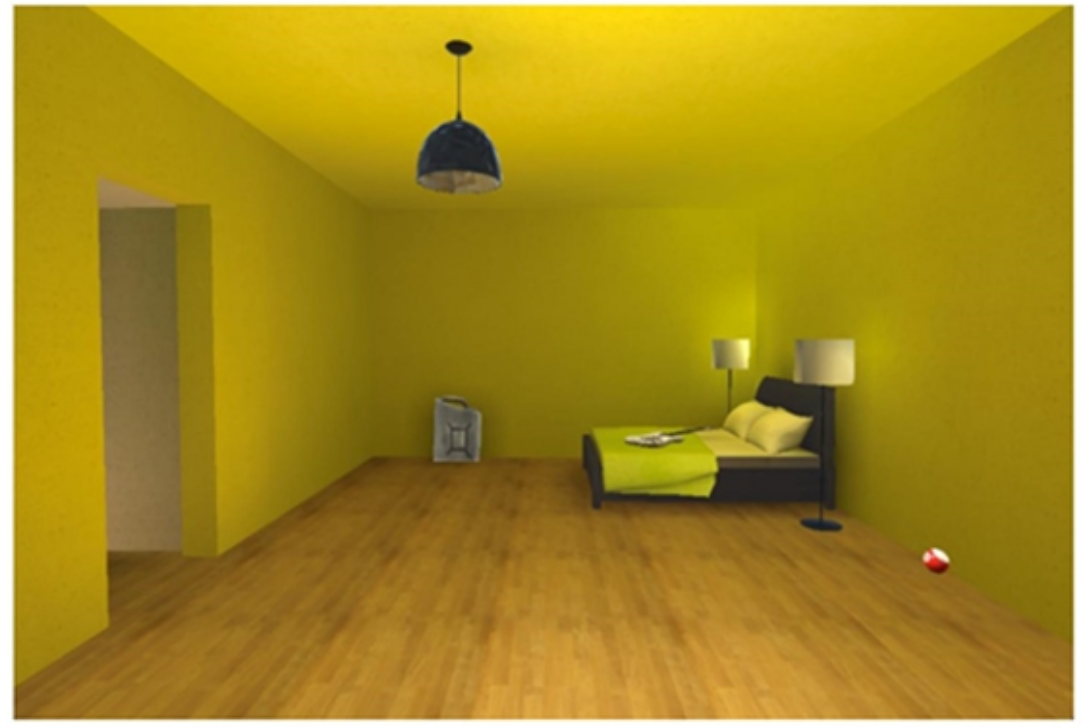

Figure 2. Ascreenshot of one of the rooms in the bungalow

In the tradition of quantitative research, this study is based on the following hypotheses: There is no significant difference in the creativity skills of participants with dyslexia and nondyslexic participants when assessed through the use of the TTCT $\left(\mathrm{H}_{0} 1\right)$. There is no significant difference in the visuo-spatial skills of adolescents with dyslexia and non-dyslexic adolescents when assessed through the use of a papertest medium, the Spatial Reasoning Test (Smith \& Lord, 2002a) $\left(\mathrm{H}_{0} 2\right)$. There is no significant difference in the visuo-spatial abilities of dyslexic and non-dyslexic adolescents when assessed through a virtual environment test medium, the Virtual Bungalow test $\left(\mathrm{H}_{0} 3\right)$.

\section{Statistical procedures}

The TTCT was scored according to published guidelines (Torrance, Ball, \& Safter, 2008) and the scoring generated five standard scores. These were Fluency, Originality, Elaboration, Abstractness of Titles and Resistance to Premature Closure. The age-appropriate section of the Spatial Reasoning Test (Smith \& Lord, 2002a) used in this study was scored according to 
the published guidelines (Smith \& Lord, 2002b). Scoring generated five subtest scores; Hidden Shapes, Sections, Jigsaws, Wallpaper and Right Angles. The Virtual Bungalow test is an adaptation of the test used by Attree et al. $(1996,2009)$ and Brooks, Attree, Rose, Clifford, and Leadbetter (1999). The scoring generated three subtest scores; Object Memory, Spatial Memory and Object-Location Memory.

The IBM $®$ Statistical Package for the Social Sciences release 23 (SPSS $\otimes$ ) was used for statistical data analysis. The data analysis included assessment of distributions (normality) with the Shapiro-Wilk test. Assessment for normality of data is a prerequisite for many statistical tests because a normal spread of scores along the Gaussian curve is an underlying assumption in parametric testing. In this test, the null hypothesis is that the data are normally distributed. At alpha level 0.05 , with a p-value of less than 0.05 , the null hypothesis that the data are normally distributed is rejected. When scores were found to be normally distributed, parametric test analysis could be performed to explore any differences between groups; otherwise, corresponding non-parametric tests were used in line with Cramer (1998). In the present data set, when the scores were found to be normally distributed, an independent samples t-test was used to assess the differences between the two groups in their creativity and visuo-spatial skills. A t-test compares two sets of scores for significant differences between them. An independent samples $t$-test compares two sample means for significant differences from different but matched populations, which was the case in this study. When scores were not normally distributed and the assumption of normality of distribution of scores was violated, the corresponding non-parametric test, the Mann-Whitney $U$ test was adopted (Cramer, 1998). The Mann-Whitney U test compares differences on an ordinal scale between two independent groups when the dependent variable is not normally distributed. Leard Statistics, an online statistics support site, lists three important assumptions for the use of this test apart from non-normal data distribution; the dependent variable should be ordinal or continuous, the independent variable should consist of two categorical, independent groups and there must be different participants in each group with no participant being in more than one group (Statistics.laerd.com, 2018). These assumptions were respected in this study.

\section{Results}

Table 1 contains a summary of the gender distribution of the sample, mean chronological age, and mean reading comprehension scores. The group of participants studied was equally balanced in terms of having dyslexia and not having dyslexia but it was not possible to have as many females as males in the study. This was not surprising given that more male learners are identified as having dyslexia than female learners (Rutter et al., 2004). The results confirm the expected discrepancy in reading ability between dyslexic and non-dyslexic learners. At average age 13 years and 4 months, the reading comprehension age of the dyslexic participants was more than 1 standard deviation below the national mean, whilst that of the non-dyslexic matched group was exactly as the national mean whilst indicated. As a group, the variability of the reading scores of the dyslexic participants varied considerably more than the variability of the non-dyslexic group, with the former having a larger standard deviation. The closeness of the two groups for age and its narrow standard deviation attests to the homogeneity of the two groups in terms of age.

Table 1. Participants' age and literacy scores

\begin{tabular}{lcc}
\hline & Dyslexic participants & Non-dyslexic participants \\
\hline Males & $\mathrm{N}=22$ & $\mathrm{~N}=22$ \\
\hline Females & $\mathrm{N}=16$ & $\mathrm{~N}=16$ \\
\hline Total & $\mathrm{N}=38$ & $\mathrm{~N}=38$ \\
\hline Mean age in months (SD) & $160(10.1)$ & $160(9.6)$ \\
\hline Mean age in years & 13 years 4 months & 13 years 4 months \\
\hline $\begin{array}{l}\text { Mean score in reading comprehension }- \\
\text { Suffolk (SD) }\end{array}$ & $79.1(8.67)$ & \multirow{2}{*}{$99.08(5.98)$} \\
\hline
\end{tabular}

\section{Torrance Tests of Creative Thinking}

When the scores of the TTCT were assessed for normality, the majority were normally distributed, with only two exceptions; Elaboration and Abstractness of Titles. These two measures required analysis through non-parametric tests. Comparison of the standardised means obtained by both groups on each subtest shows that differences were not significant. These results are shown below, using independent samples t-tests and the Mann-Whitney $U$ 
test as appropriate.

Table 2. Mean scores, t-test and Mann-Whitney $U$ test results for the TTCT

\begin{tabular}{|c|c|c|c|c|c|c|}
\hline \multicolumn{2}{|l|}{ Group } & $\begin{array}{l}\text { TTCT- } \\
\text { Fluency }\end{array}$ & $\begin{array}{l}\text { TTCT- } \\
\text { Originality }\end{array}$ & $\begin{array}{l}\text { TTCT- } \\
\text { Resistance to } \\
\text { Premature } \\
\text { Closure }\end{array}$ & $\begin{array}{l}\text { TTCT- } \\
\text { Elaboration }\end{array}$ & $\begin{array}{l}\text { TTCT- } \\
\text { Abstractness of } \\
\text { Titles }\end{array}$ \\
\hline \multirow{2}{*}{$\begin{array}{l}\text { Dyslexic } \\
\mathrm{n}=38\end{array}$} & Mean & 103 & 98.8 & 76.2 & 83.7 & 81.8 \\
\hline & $\mathrm{SD}$ & 15.2 & 15.6 & 18.0 & 15.2 & 22.2 \\
\hline \multirow{2}{*}{$\begin{array}{l}\text { Non-dyslexic } \\
\mathrm{n}=38\end{array}$} & Mean & 98.2 & 96.2 & 68.7 & 84.5 & 77.5 \\
\hline & SD & 21.3 & 23.7 & 17.3 & 18.3 & 16.7 \\
\hline \multicolumn{2}{|c|}{ Independent-samples t-test } & $1.064, \mathrm{~ns}$ & $.566, \mathrm{~ns}$ & $1.838, \mathrm{~ns}$ & & \\
\hline \multicolumn{2}{|c|}{ Mann-Whitney U test } & & & & 708.5 & $642.5, \mathrm{~ns}$ \\
\hline
\end{tabular}

Note. $\mathrm{ns}=$ not significant.

\section{Spatial Reasoning Tests}

Only one of the five component scores of this test, Hidden Shapes was normally distributed; the score distributions of the other four subtests (Sections, Jigsaws, Wallpaper and Right Angles) had a non-normal distribution with p-values less than the 0.05 criterion on the Shapiro-Wilk test. Two of the three component scores of the Virtual Bungalow test, Object Memory and Spatial Memory also had a non-normal distribution.

There were no significant differences between the scores of the dyslexic and the nondyslexic groups on any of the Spatial Reasoning subtests as shown in Table 3 below. Here, it appears that the two groups were not performing any differently from one another with no discernible consistency in the pattern of scores achieved or the standard deviation of each subtest score.

Table 3. Mean scores, t-test and Mann-Whitney test results for the Spatial Reasoning Tests

\begin{tabular}{|c|c|c|c|c|c|c|}
\hline \multicolumn{2}{|l|}{ Group } & $\begin{array}{l}\text { Hidden } \\
\text { Shapes }\end{array}$ & Sections & Jigsaws & Wall-paper & Right Angles \\
\hline \multirow{2}{*}{$\begin{array}{l}\text { Dyslexic } \\
\mathrm{n}=38\end{array}$} & Mean & 97.3 & 101 & 99.3 & 100 & 96.6 \\
\hline & SD & 16.6 & 14.3 & 15.9 & 15.1 & 14.0 \\
\hline \multirow{2}{*}{$\begin{array}{l}\text { Non-dyslexic } \\
\mathrm{n}=38\end{array}$} & Mean & 98.5 & 99.2 & 101 & 99.8 & 103 \\
\hline & SD & 12.9 & 15.8 & 14.3 & 15.1 & 15.3 \\
\hline \multicolumn{2}{|c|}{ Independent-samples t-test } & $-1.61, \mathrm{~ns}$ & & & & \\
\hline \multicolumn{2}{|c|}{ Mann-Whitney U test } & & $666, \mathrm{~ns}$ & $681, \mathrm{~ns}$ & $704, \mathrm{~ns}$ & $554, \mathrm{~ns}$ \\
\hline
\end{tabular}

\section{Virtual Bungalow Test}

This test yielded three different measures: Object Memory, Spatial Memory and ObjectLocation Memory. Results presented in Table 4 show that there were no significant differences between the scores of the dyslexic and the non-dyslexic groups.

Table 4. Mean scores, t-test and Mann-Whitney test results for the Virtual Bungalow test

\begin{tabular}{lllll}
\hline Group & & Object Memory & Spatial Memory & $\begin{array}{l}\text { Object-Location } \\
\text { Memory }\end{array}$ \\
\hline $\begin{array}{l}\text { Dyslexic } \\
\mathrm{n}=38\end{array}$ & Mean & 97.3 & 101.1 & 99.4 \\
\cline { 2 - 5 } $\begin{array}{l}\text { Non-dyslexic } \\
\mathrm{n}=38\end{array}$ & $\mathrm{SD}$ & 17.6 & 13.5 & 14.8 \\
\cline { 2 - 5 } & Mean & 102.7 & 98.9 & 100.6 \\
\hline Independent-samples t-test & $\mathrm{SD}$ & 11.4 & 16.4 & $-.370, \mathrm{~ns}$ \\
\hline Mann-Whitney U test & & & & $69, \mathrm{~ns}$ \\
\hline
\end{tabular}

Note. ns = not significant.

\section{Discussion}

\section{Limitations}

Prior to discussing the results, one must describe the limitations of this study and the effect these could have on the generalizability and applicability of the results attained. The study 
suffers from a number of inherent but unavoidable limitations. The first is the fact that the IQ of the non-dyslexic group is being assumed rather than measured, albeit based on school performance and a measure of reading comprehension. Furthermore, one cannot eliminate slight variations in the measurement of the dyslexic participants' IQ due to their having been assessed by different psychologists and not necessarily all using the same test, with the BAS and the WISC being the most commonly used IQ tests in Malta. The fact that the participants are bilingual students receiving code-switched instructions for the reasons identified by Gauci and Camilleri Grima (2012) may have contributed to a departure from standard test administration and this could have affected the results somewhat. This variation on the standard procedure applies to all measures where verbal instructions are given, be it ability testing or any of the assessments administered by the researchers in this study. Like in many other small studies of its kind, the researchers could only recruit a small number of individuals with dyslexia. Although the actual numbers of such students on the register of the Specific Learning Difficulties Service is considerable (within the limits of a state school population of around 2,000 twelve to fourteen-year-olds) the actual number of students available who had a significant reading age discrepancy and who were willing to participate was considerably smaller. Finally, some leeway was allowed in the selection of participants in a bid to combat low sample numbers; one or two participants with a reading comprehension score of between 85 and 90 , rather than a score below 85 deviation points, were included in the research group. All results must be evaluated against the backdrop of these limitations.

\section{No evidence of differences on the creativity measures}

Overall, no evidence was found to support the hypothesis that individuals with dyslexia possessed any superior nonverbal creative skills when matched with the comparison group and null hypotheses $\mathrm{H}_{0} 1$ was supported. The dataset points to the conclusion that in the context of creativity as measured in this study, having dyslexia is not associated with enhanced figural creativity. Conversely, non-dyslexic participants in this study did not possess significantly higher creativity than their dyslexic matches. Within its limitations, this study does not support the results reported by Tafti et al. (2009) even if the measures used were identical and populations were comparable. While Symonds (2005), Winner et al. $(1991,2001)$ and Wolff and Lundberg (2002) made claims for students with dyslexia being attracted to art and design-related disciplines, these claims referred to young adults rather than young adolescents. Other reported successes of individuals with dyslexia in areas of endeavour requiring creativity, as reported by McLoughlin et al. $(1994)$ and Everatt et al. $(1999,2008)$ are also limited to adults. Neither do the present results support Ritchie et al.'s (2013) and Wolf's (2011) claims that weak literacy seems to be associated with lower, rather than higher scores on all measures of creativity as no discernible difference was found between the two groups. Another valid interpretation of the results is that they can be inferred to support Baer's (2011a, b) opinion that the TTCT tests may only assess particular aspects of creativity and as such, the type of creativity they assess is not the one witnessed in everyday life situations as described in Everatt et al. (1999, 2008). Possibly, a clear endowment in creativity may be evident in real life situations such as art and design and problem management scenarios or other contrived conditions. The bottom line is that the results of the creativity section of this study support the latest combined findings published in Chamberlain et al.'s (2018) meta-analytical study. Consequently, no evidence was found to reject the first null hypothesis $\left(\mathrm{H}_{0} 1\right)$ posited above and this was retained.

\section{No evidence of differences on the visuo-spatial measures}

In the second set of analyses related to spatial reasoning using two-dimensional tests on paper (Spatial Reasoning Test), there were no significant differences between the scores of the dyslexic and the non-dyslexic groups. Analyses revealed that dyslexic participants performed similarly to non-dyslexic participants in all domains of spatial reasoning as assessed for by this test. Therefore, the second null hypothesis $\left(\mathrm{H}_{0} 2\right)$ was retained. The results obtained for this two-dimensional test of spatial awareness on paper was in conformity with results obtained bya number of researchers (Winner et al. (2001); Helland \& Asbjørnsen (2003); Brunswick et al. (2010); Duranovic et al. (2015)). These showed that on the twodimensional tests of visuo-spatial ability on paper, participants with dyslexia did not have a clear advantage over the matched non-dyslexic participants.

The third set of analyses indicated that there were no significant differences between the scores of the dyslexic and the non-dyslexic groups on any of the subtests of the Virtual 
Bungalow test. Adolescents with dyslexia performed similarly to their matches without dyslexia in all three measures. Therefore, the third null hypothesis $\left(\mathrm{H}_{0} 3\right)$ was retained. In this sample of 12 to 14-year-old participants, there were no statistically significant differences between the two groups in their visuo-spatial skills when assessed through a virtual environment test medium. The results obtained from the analysis of the visuo-spatial tests (Spatial Reasoning Test and Virtual Bungalow Test) diverge somewhat from those of Attree et al. (2009), Von Károlyi (2001), Von Károlyi et al. (2003), and Wang and Yang (2011). In these studies, researchers registered a significant difference in their assessment of participants with and without dyslexia, be this visuo-spatialability or speed. This is something this present study did not establish and where it is clearly at odds with previous studies. Even so, the limitations of the present study may have diminished its power to identify differences between the two groups.

\section{Conclusions and Implications}

In accordance with the general outcomes of two large recent meta-analytical studies (Gilger et al., 2016; Chamberlain et al., 2018), the present findings do not provide support for superior creativity or visuo-spatial talent in the group of dyslexic participants assessed. This study assessed only a few aspects of creativity and visuo-spatial expression and findings are bound by the specific measures used, the method of administration, and the small number of participants. The results of this study also suggest that creativity and visuo-spatial ability are highly complex cognitive factors that are respectively varied (Torrance et al. 2008) and difficult to measure and compare (Carroll, 1993). In future, research could be look in the direction of practical creative problem solving and real-lifevisuo-spatial tasks such as map reading, navigation and geolocation to further explore the possibility of the Geschwind and Galaburda (1987) pathology of superiority theory.

The results of this study have some practical implications that are useful for teachers in particular. Results indicate that teachers should not expect young children and adolescents with dyslexia to possess any particular creative or visuo-spatial skills that could in any way compensate for their literacy difficulties. They should not assume that any superior creativity or visuo-spatial awareness is to be expressed in school-based subjects that are not language based. All learners, irrespective of their situation should be helped to use their strengths and develop good self-efficacy in scholastic subjects. Indeed, all should be encouraged to use their creative potential and to experiment with three-dimensional objects, computer games and art in general through multisensory teaching that is structured and sequential. All dyslexic children should be specifically supported in their achievement issues like other children with other needs and should be encouraged to develop interests that may, in future prove to be stepping-stones to adult careers. As much effort as possible should be invested in children with dyslexia to help them develop any other skills that they possess; because, in the absence of good literacy skills, they cannot depend on having compensatory strengths. This should mitigate the demoralising and disheartening effect of dyslexia and its corollaries so clearly described in Beddington et al. (2008).

\section{Acknowledgment}

I acknowledge the contribution by Doriella Camilleri and Deidre Fenech who recruited and assessed the participants in this study and collated the data.

\section{References}

Attree, E. A., Brooks, B.M., Rose, F.D., Andrews, T.K., Lead better, A.G., \& Clifford, B.R. (1996). Memory processes and virtual environments: I can't remember what was there, but I can remember how I got there. Implications for people with disabilities. Proceedings of the ECDVRAT: First European Conference on Disability, Virtual Reality and Associated Technologies, 117-121. Retrieved from: http://www.icdvrat.org/1996/papers/1996_14.pdf

Attree, E., Turner, M. J., \& Cowell, N. (2009). A virtual reality test identifies the visuospatial strengths of adolescents with dyslexia. Cyber Psychology and Behaviour, 12(2), 163-168.doi: 10.1089/cpb.2008.0204

Baddeley, A. D. \& Hitch, G. (1974). Working memory. In G.H. Bower (Ed.), The psychology of learning and motivation: Advances in research and theory (Vol. 8, pp. 47-89). New York: Academic Press. 
Baer, J. (2001a). How divergent thinking tests mislead us: are the Torrance Tests still relevant in the 21st century? The division 10 debate. Psychology of Aesthetics, Creativity, and the Arts, 5(4), 309-313. doi:10.1037/a0025210

Baer, J. (2001b). Four (more) arguments against the Torrance Tests. Psychology of Aesthetics, Creativity, and the Arts, 5(4), 316-317. doi:10.1037/a0025211

Barbiero, C., Lonciari, I., Montico, M., Monasta, L., Penge, R., Vio, C.,...Ronfani, L. (2012). The Submerged Dyslexia Iceberg: How Many School Children Are Not Diagnosed? Results from an Italian Study. PLoS ONE, 7(10), 1-9.doi:10.1371/journal.pone.0048082

Battista, M.T. (2007). The Development of Geometric and Spatial Thinking. In F. K. Lester, Jr. (Ed.), Second handbook of research on mathematics teaching and learning (pp 843-908). Charlotte, NC: Information Age Publishing.

Beddington, J., Cooper, C.L., Field, J., Goswami, U., Huppert, F.A., Jenkins, R.,...Thomas, S.M., (2008). The mental wealth of nations. Nature, 455, 1057-1060. doi:10.1038/4551057a

Brincat, B. (2017). The development of literacy skills in Maltese-English bilingual children (Unpublished master's dissertation). The University of Malta.

Brooks, B.M, Attree, E.A., Rose, F.D., Clifford, B.R., \& Lead better, A.G. (1999). The specificity of memory enhancement during interaction with a virtual environment. Memory, 7(1), 65-78.doi:10. 1080/741943713

Brunswick,N., Martin, G.N., \& Marzano, L. (2010). Visuospatial superiority in developmental dyslexia: myth or reality? Learning and Individual Differences, 20(5), 421-426.doi:10.1016/j.lindif.2010.04.007

Bryden, M.P., Mcmanus, I.C., \& Bulman-Fleming, M.B. (1994). Brain and Cognition, 26(2), 103-167.

Cain, K. (2010). Reading Development and Difficulties. Chichester, British Psychological Society and Blackwell Publishing.

Carroll, J. B. (1993). Human Cognitive Abilities: A survey of factor-analytic studies. Australia, AU: Cambridge University Press, Australia.

Chamberlain, R., Brunswick, N., Siev, J., \& McManus, I.C. (2018). Meta-analytic findings reveal lower means but higher variances in visuospatial ability in dyslexia. British Journal of Psychology. Advance online publication.doi:10.1111/bjop.12321

Chávez-Eakle, R. A. (2010). The relevance of creativity in education. New Horizons for Learning 7, 1. Retrieved from:http://jhepp.library.jhu.edu/ojs/index.php/newhorizons/article/view/71/69>

Clapham, M.M. (2004). The convergent validity of the Torrance tests of creative thinking and creativity interest inventories. Educational and Psychological Measurement, 64(5), 828-841.doi:10.1177/ 0013164404263883

Cockcroft, K. \& Hartgill, M. (2004). Focusing on the abilities in learning disabilities: Dyslexia and creativity. Education as Change, 8(1), 61-79.

Cramond, B., Matthews-Morgan, J., Torrance, P., \& Zuo, L. (1999). Why should the Torrance Tests of Creative Thinking be used to assess creativity? The Korean Journal of Thinking \& Problem Solving, 9(2), 77-101.

Cramer, D. (1998). Fundamental Statistics in Social Research. London, UK: Routledge.

Davis, R.D.\& Braun, E.M. (2010). The gift of dyslexia-updated. New York, NY: Perigee.

Diakidoy, I.-A.A. \& Spanoudis, G. (2002). Domain Specificity in Creativity Testing: A Comparison of Performance on a General Divergent-Thinking Test and a Parallel, Content-Specific Test. Journal of Creative Behavior, 36(1), 41-61.

Duranovic, M., Dedeic, M. \& Gavrić, M. (2015). Dyslexia and Visual-Spatial Talents. Current Psychology, 34(2), 207-222.doi:10.1007/s12144-014-9252-3

Eisen, M. L. (2001). Assessing differences in children with learning disabilities and normally achieving students with a new measure of creativity. Journal of Learning Disabilities, 22(7), 462-464.doi: $10.1177 / 002221948902200715$

Ekstrom, R. B., French, J. W., Harman, H. H., \& Dermen, D. (1976). Kit of factor-referenced cognitive tests. Educational Testing Service, Princeton.

Elliott, J. (2005). Dyslexia: Diagnoses, debates and diatribes. Special Children, 169, 19-23.

Elliott, J. \& Place, M. (2004). Difficulties in children, London, UK: Routledge. 
Elliott, J. G. \& Gibbs, S. (2008). Does dyslexia exist? Journal of Philosophy of Education, 42, 475-491.doi: $10.1108 / \mathrm{S} 0735-004 \mathrm{X}(2010) 0000023013$

Everatt, J., Steffert, B., \& Smythe, I. (1999). An eye for the unusual: Creative thinking in dyslexics. Dyslexia, 5, 24-46.doi:10.1002/(SICI)1099-0909(199903)5:1<28::AID-DYS126>3.0.CO;2-K

Everatt, J., Weeks, S.,\& Brooks, P. (2008). Profiles of strengths and weaknesses in dyslexia and other learning difficulties. Dyslexia, 14, 16-41.doi:10.1002/dys.342

Firman, C. (2009). Perspectives from Malta. Perspectives on Language and Literacy, 35(1), $28-31$. Retrieved from:https://search-proquest-com.ejournals.um.edu. $\mathrm{mt}$ docview/200229019? accountid $=27934$

Galaburda, A. M. \& Kemper, T. L. (1979).Cytoarchitectonic abnormalities in developmental dyslexia: A case study. Annals of Neurology, 5(2), 94-100. doi:10.1002/ana.410060203

Galaburda, A. M., Sherman, G. F., Rosen, G. D., Aboitiz, F., \& Geschwind, N. (1985). Developmental Dyslexia: Four Consecutive Patients with Cortical Anomalies. Annals of Neurology, 18, 222-233.

Gardner, H. (1993). Frames of Mind: The Theory of Multiple Intelligences. New York, NY: Basic Books.

Gauci, H. \& Camilleri Grima, A. (2012). Codeswitching as a tool in teaching Italian in Malta, International Journal of Bilingual Education and Bilingualism, 16(5),615-631. doi: 10.1080/13670050.2012.716817

Geschwind, N. \& Galaburda, A. M. (1987). Cerebral lateralisation: Biological mechanisms, associations, and pathology. Cambridge, MA: MIT Press.

Gilger, J.W., Allen, K., \& Castillo, A. (2016). Reading disability and enhanced dynamic spatial reasoning: A review of the literature. Brain and Cognition, 105,55-65. doi: 10.1016/j.bandc.2016.03.005

Grech, L. (2011). Reading Comprehension in Maltese-English Bilinguals. (Unpublished doctoral dissertation). University of Surrey, UK.

Guilford, J.P. (1966). Measurement and Creativity. Theory into Practice, 5(4), 186-189, 202.

Hagley, F. J. (2002). Suffolk Reading Scale: Version 2. Granada Learning Group. London.

Helland, T. \& Asbjørnsen, A. (2003). Visual-sequential and visuo-spatial skills in dyslexia: Variations according to language comprehension and mathematics skills. Child Neuropsychology, 9(3), 208-220. doi: 10.1076/chin.9.3.208.16456

Kaufman,J.C., Plucker, J.A., \& Baer, J. (2008). Essentials of Creativity Assessment. New Jersey, NJ: John Wiley and Sons.

Kim, K. H. (2006). Can we trust Creativity Tests? A review of the Torrance Test of Creative Thinking (TTCT). Creativity Research Journal, 18(1), 3-14.doi:10.1207/s15326934crj1801_2

Kozbelt, A., Beghetto, R.A., \& Runco, M.A. (2010). Theories of Creativity. In: J.C. Kaufman \& R.J. Sternberg, (Eds.), Cambridge Handbook of Creativity, New York, NY: Cambridge University Press, 20-47.

Lohman, D. F. (1994). Spatially gifted, verbally inconvenienced. In N. Colangelo, S.G. Assouline, \&D.L. Ambroson, (Eds.), Talent Development: Vol 2. Proceedings from the 1993 Henry B. and Jocelyn Wallace National Research Symposium on Talent Development, Dayton, OH: Ohio Psychology Press, 251-264.

Lubinski, D. (2010). Spatial ability and STEM: A sleeping giant for talent identification and development. Personality and Individual Differences, 49, 344-351.doi:10.1016/j.paid.2010.03.

Lyon, G.R., Shaywitz, S. E., \& Shaywitz, B.A. (2003). Defining dyslexia, comorbidity, teachers' knowledge of language and reading. Annals of Dyslexia, 53, 1-14. Retrieved from https://search-proquestcom.ejournals.um.edu.mt/docview/225373075?accountid=27934

Martinelli, V. (1996). Early metalinguistic abilities and subsequent reading and spelling achievements of Maltese children. (Unpublished doctoral dissertation), University of Manchester, UK.

Martinelli, V. \& Schembri, J. (2015). Dyslexia and creativity in Maltese male adolescents. DECP Debate 156, September, British Psychological Society, Leicester, UK, 21-32.

McLoughlin, D., Fitzgibbon, G., \& Young, V. (1994). Adult dyslexia: Assessment, counselling and training. Whurr, London.

Miles, T.R. (1993). Dyslexia: The pattern of difficulties (2nd ed.). Whurr, London.

Mohler, J. L. (2008). A review of spatial ability research. Engineering Design Graphics Journal, 72, 19-30.

Niolaki, G. \& Masterson, J. (2012). Transfer effects in spelling from transparent Greek to opaque English in seven-to-ten-year-old children. Bilingualism: Language and Cognition, 15(4), 757-770. doi:10.1017/S1366728911000721 
National Statistics Office (Malta). (2016). Students Enrolments: 2014/2015, News Release 202/2016.Dissemination Unit, National Statistics Office, Valletta, Malta. Retrieved from: https://nso.gov.mt/en/News_Releases/View_by_Unit/Unit_C4/Education_and_Information_Society_Stati stics/Documents/2016/News2016_202.pdf

Office for National Statistics (UK). The National Statistics Socio-economic classification (NS-SEC). Retrieved from:https://www.ons.gov.uk/methodology/classificationsandstandards/otherclassifications/t henationalstatisticssocioeconomicclassificationnssecrebasedonsoc2010\#classes-and-collapses

Peterson, R.L. \& Pennington, B.F. (2012). Developmental dyslexia. Lancet, 379, 1997-2007. doi: 10.1016/S0140-6736(12)60198-6.

Plucker, J. A. \& Makel, M. C. (2010). Assessment of creativity. In J.C. Kaufman \& R.J. Sternberg, (Eds.), The Cambridge Handbook of Creativity, New York, NY: Cambridge University Press , 48-73.

Rice, M. \& Brooks, G. (2004). Developmental dyslexia in adults: A research review. London, National Research and Development Centre. Retrieved from: http://dera.ioe.ac.uk/22476/1/doc_166.pdf

Rimland, B. \& Fein, D. (1988). Special talents and autistic savants. In: L.K. Obler \& D. Fein,(Eds.), The exceptional brain: Neuropsychology of talent and special abilities, New York, NY: Guilford Press, 374-492.

Ritchie, S., Luciano, M., Hansell, N., Wright, M., \& Bates, T. (2013). The relationship of reading ability to creativity: Positive, not negative associations. Learning and Individual Differences, 26, 171-176.doi. 10.1016/j.lindif.2013.02.009

Rizzo, A.A., Parsons, T.D., Kenny, P., \& Buckwalter, J.G. (2012). Using Virtual Reality for Clinical Assessment and Intervention. In L. L'Abate, \& D. Palmer, (Eds.) Handbook of Technology in Psychology, Psychiatry, and Neurology: Theory, Research, and Practice, New York, NY:Nova Science Publishers, 277318.

Rose, J. (2009). Identifying and teaching children and young people with dyslexia and literacy difficulties. Retrieved from: http://www.thedyslexia-spldtrust.org.uk/media/downloads/inline/the-rosereport.1294933674.pdf

Runco, M. A. (1990). Implicit theories and ideational creativity. In M.A. Runco \& R.S. Albert (Eds.), Theories of creativity (pp. 61-91). Newbury Park, CA: Sage.

Runco, M.A., Millar, G., Acar, S., \& Cramond, B. (2010). Torrance Tests of Creative Thinking as Predictors of Personal and Public Achievement: A Fifty-Year Follow-Up. Creativity Research Journal, 22(4), 361-368.doi: $10.1080 / 10400419.2010 .523393$

Rutter, M., Caspi, A., Fergusson, D., Horwood, L.J., Goodman, R., Maughan, B., ... Carroll, J. (2004). Sex differences in developmental reading disability: new findings from 4 epidemiological studies. The Journal of the American Medical Association, 291(16), 2007-2012. doi:10.1001/jama.291.16.2007.

Sciriha, L. \& Vassallo, M. (1998). Images of Social Class through Language in Malta. Plurilinguismes: Des Iles et des Langues, Universite Rene Descartes, 15, 171-199.

Shea, D. L., Lubinski, D., \& Benbow, C. P. (2001). Importance of assessing spatial ability in intellectually talented young adolescents: A 20-year longitudinal study. Journal of Educational Psychology, 93(3), 604-614.doi:10.1037/0022-0663.93.3.604

Sherman, G. F. \& Cowen, C. D. (2010).Norman Geschwind: A Man Out of Time. Perspectives on Language and Literacy, 36(1), 14-17. Retrieved from: https://www.scoop.it/t/dyslexia-diablogue-ida-examiner/ p/4038926428/2015/03/11/norman-geschwind-a-man-out-of-time-with-comment-on-cerebrodiversity-idaperspectives-2010

Siegel, L. (2006). Perspectives on dyslexia. Paediatrics and Child Health, 11(9), 581-587.doi:10. 1093/pch/11.9.581

Smith, P. \& Lord, T. (2002a). Spatial Reasoning Test 12-14. Granada Learning and Assessment, London.

Smith, P. \& Lord, T. (2002b). Spatial Reasoning (Age: 12-14) Teacher's Guide. Granada Learning and Assessment, London.

Statistics.laerd.com. (2018). Mann-Whitney U Test using SPSS Statistics. [online] Available at: https://statistics.laerd.com/spss-tutorials/mann-whitney-u-test-using-spss-statistics.php

Sun, Y. F., Lee, J. S., \& Kirby, R. (2010). Brain Imaging Findings in Dyslexia. Pediatrics and Neonatology, 51(2), 89-96.doi: 10.1016/S1875-9572(10)60017-4

Symonds, H. (2005). Designing effective curriculum for dyslexic students within art and design in higher education. London College of Communication, University of the Arts, London.Retrieved from: http://ualresearchonline.arts.ac.uk/485/1/Designing_effective_curriculum_for_dyslexic_st-1.pdf 
Tafti, M. \& Faizipour, H. (2005). Dyslexia as a gift. Tehran: Alzahra University Publications.

Tafti, M., Hameedy, M., \& Baghal, N. (2009). Dyslexia, a deficit or a difference: Comparing the creativity and memory skills of dyslexic and nondyslexic students in Iran. Social Behavior \& Personality: An International Journal, 37(8), 1009-1016.doi: 10.2224/sbp.2009.37.8.1009

Torrance, E. P. (1966). The Torrance Tests of Creative Thinking-Norms-Technical Manual Research EditionVerbal Tests, Forms A and B-Figural Tests, Forms A and B. Princeton, NJ: Personnel Press.

Torrance, E. P. (1990). The Torrance Tests of Creative Thinking-Norms-Technical Manual Figural (Streamlined) Forms A \& B. Bensenville, IL: Scholastic Testing Service Inc.

Torrance, E. P. (1998). Torrance Test of Creative Thinking. Norms-technical manual-figural (Streamlined) Forms $A$ and B. Bensenville, IL: Scholastic Testing Service Inc.

Torrance, E. P., Ball, O. E., \& Safter, H. T. (2008). Torrance Tests of Creative Thinking: Streamlined Scoring Guide for Figural Forms A and B. Bensenville, IL: Scholastic Testing Service Inc.

Tosto, M., Hanscombe, K. B., Haworth, C., Davis, O., Petrill, S., Dale, P., ... Kovas, Y. (2014). Why do spatial abilities predict mathematical performance? Developmental Science, 17(3), 462-470.doi: $10.1111 /$ desc. 12138

Unity Technologies ApS. (2015). Unity 5.2.0. Retrieved from: https://unity3d.com/get-unity/download /archive?_ga=1.119541000.1642573073.1478428817

University of Malta \& Ministry of Education. (2010). Reading Comprehension and Spelling Tests in Maltese and English. University Printing Office, Msida, Malta.

Vidyasagar, T. \& Pammer, K. (2009). Dyslexia: A deficit in visuo-spatial attention, not in phonological processing. Trends in Cognitive Sciences, 14(2), 57-63.doi:10.1016/j.tics.2009.12.00

Villalba, E. (2012). Searching for the holy grail of measuring creativity. Creativity Research Journal, 24(1), 1-2. doi: $10.1080 / 10400419.2012 .649235$

Von Károlyi, C. (2001). Visual-Spatial Strength in Dyslexia: Rapid discrimination of impossible figures. Journal of Learning Disabilities, 34(4), 380-391.doi:10.1177/002221940103400413

Von Károlyi, C., Winner, E., Gray, W., \& Sherman, G. (2003). Dyslexia linked to talent: Global visual-spatial ability. Brain and Language, 85(3), 427-431.doi:10.1016/S0093-934X(03)00052-X

Wang, L. \& Yang, H. M. (2011). The comparison of the visuo-spatial abilities of dyslexic and normal students in Taiwan and Hong Kong. Research in Developmental Disabilities, 32, 1052-1057. doi:10.1016 /j.ridd.2011.01.028

Wang, X. (2016). The Effect of Language Ability in Creativity Assessment. (Unpublished master's dissertation). University of Minnesota. USA.

West, T. (1999). The abilities of those with reading disabilities: focusing on the talents of people with dyslexia. In D.D. Duane(Ed.), Reading and attention disorders - neurobiological correlates, Baltimore: York Press, 213-141.

West, T. G. (1991). In the Mind's Eye: Visual thinkers, gifted people with learning difficulties, computer images, and the ironies of creativity. Buffalo, New York, NY: Prometheus Books.

Williams, J. \& O'Donovan, M.C. (2006). The genetics of developmental dyslexia. European Journal of Human Genetics, 14, 681-689.doi:10.1038/sj.ejhg.5201575

Winner, E., Casey, M., Dasilva, D., \& Hayes, R. (1991). Spatial abilities and reading deficits in visual art students. Empirical Studies of the Arts, 9(1), 51-63.doi:10.2190/528M-DXT5-WUJA-W297

Winner, E., von Karolyi, C., Malinsky, D., French, L., Seliger, C., Ross, E., \& Weber, C. (2001). Dyslexia and visual-spatial talents: Compensation vs deficit model. Brain and Language, 76(2), 81-110.doi: 10.1006/brln.2000.2392

Wolff, U. (2011). Artistic talents and dyslexia: A genuine connection? In Alexander-Passe, N. (Ed.), Dyslexia and creativity: Investigations from differing perspectives. New York, NY: Nova Publishers, 65-77.

Wolf, U. \& Lundberg, I. (2002). The prevalence of dyslexia among art students. Dyslexia, 8, 34-42.doi:10.1002/dys.211s 